\title{
Refractory lympho-epithelial carcinoma of the nasopharynx: a case report illustrating a protracted clinical course Frederick Y Wu ${ }^{\dagger 1,2}$, Eddy S Yang ${ }^{\dagger 1}$, Christopher D Willey ${ }^{1}$, Kim Ely ${ }^{3}$, Gaelyn Garrett ${ }^{4}$ and Anthony J Cmelak*1
}

\begin{abstract}
Address: ${ }^{1}$ Department of Radiation Oncology, Vanderbilt University School of Medicine, Nashville, TN, USA, 2Department of Radiation Oncology, University of California at San Francisco, San Francisco, CA, USA, ${ }^{3}$ Department of Pathology, Vanderbilt University School of Medicine, Nashville, TN, USA and ${ }^{4}$ Department of Otolaryngology, Voice Center, Vanderbilt University School of Medicine, Nashville, TN, USA

Email: Frederick YWu - wufy@radonc.ucsf.edu; Eddy S Yang - eddy.yang@vanderbilt.edu;

Christopher D Willey - christopher.willey@gmail.com; Kim Ely - kim.ely@vanderbilt.edu; Gaelyn Garrett - gaelyn.garrett@vanderbilt.edu; Anthony J Cmelak* - anthony.cmelak@vanderbilt.edu

* Corresponding author †Equal contributors
\end{abstract}

Published: 15 June 2009

Head \& Neck Oncology 2009, I:18 doi:10.1 186/1758-3284-I-18
Received: 7 April 2009

Accepted: 15 June 2009

This article is available from: http://www.headandneckoncology.org/content/l////8

(C) 2009 Wu et al; licensee BioMed Central Ltd.

This is an Open Access article distributed under the terms of the Creative Commons Attribution License (http://creativecommons.org/licenses/by/2.0), which permits unrestricted use, distribution, and reproduction in any medium, provided the original work is properly cited.

\begin{abstract}
Nasopharyngeal carcinoma is an uncommon cancer in North America. Its clinical course is typified by locally advanced disease at diagnosis and has a high propensity for both regional and distant spread. It is, therefore, typically treated with a combination of radiation and chemotherapy. This report describes our 10-year clinical and radiological findings in a 48-year-old Vietnamese male patient with locally-advanced T4NIMO lympho-epithelial carcinoma of the nasopharynx. Despite a long remission period after his initial course of aggressive chemoradiation, his tumor recurred locally after 4 years. Thereafter, throughout a period of over 10 years, he has been treated with multiple courses of re-irradiation and three different trials of chemotherapy. He was ultimately provided with over 30 months of progression-free tumor control with the epidermal growth factor receptor (EGFR)-inhibitor cetuximab. This case illustrates the commonly protracted course of this disease and its responsiveness to multiple treatment modalities.
\end{abstract}

\section{Introduction}

Nasopharyngeal carcinoma (NPC) is a squamous cell carcinoma that occurs in the epithelial lining of the nasopharynx. In the United States and Western Europe, nasopharyngeal carcinoma is a relatively rare. It is more common among Southern Chinese, Southeast Asian, Northern African, and Eskimo populations [1]. Among head and neck cancers, NPC has the highest propensity for developing distant metastases. Histologies of NPC range from well-differentiated squamous carcinoma (WHO type I), to non-keratinizing squamous carcinoma (WHO type II), to lympho-epithelial carcinoma (WHO type III), where non-keratinizing squamous carcinoma cells are mixed with numerous benign lymphocytes. Type III cancers are regarded as having the highest response to treatment, but also the greatest propensity for developing distant micrometastatic spread. Due to the anatomical location of the disease, NPC is typically not treated with surgical resection; rather concurrent chemoradiotherapy is the preferred approach. Cisplatin with radiation followed by adjuvant chemotherapy has been reported to be more effective in patients with NPC than with radiation alone $[2,3]$, and this approach has now been adopted as current standard of care. Despite this combined approach, $31 \%$ of patients will develop recurrent disease[2]. 
Cetuximab, a recombinant human/mouse chimeric monoclonal antibody, binds specifically to the epidermal growth factor receptor (EGFR, HER1, c-ErbB-1) and competitively inhibits the binding of epidermal growth factor (EGF). This results in inhibition of cell growth, induction of apoptosis, and decreased matrix metalloproteinase and vascular endothelial growth factor production [4]. This drug has proven clinical benefit as a single agent in patients with recurrent or metastatic squamous cell carcinoma of head and neck [5,6]. Additionally, a phase III trial was published showing improved local control and overall survival in patients treated with cetuximab plus radiation compared to radiation alone [7].

The following case report describes a Vietnamese male with a 10-year clinical course of lympho-epithelial carcinoma of the nasopharynx who failed multiple therapies involving both chemotherapy and radiation, but was able to achieve stable disease for over 30 months with EGFR inhibition.

\section{Case report}

In October 1997, a 39 year old immigrant from Vietnam presented with right-sided headache, otalgia, and tinnitus over the previous month. He was discharged with clarithromycin for suspected otitis media. One month later, he returned with severe right otalgia which now radiated to the vertex of his skull. He re-presented with continued symptoms. Endoscopic exam revealed a large mass emanating from the nasopharynx. Biopsy was performed, with surgical pathology revealing poorly-differentiated invasive lympho-epithelial nasopharyngeal carcinoma (Figure

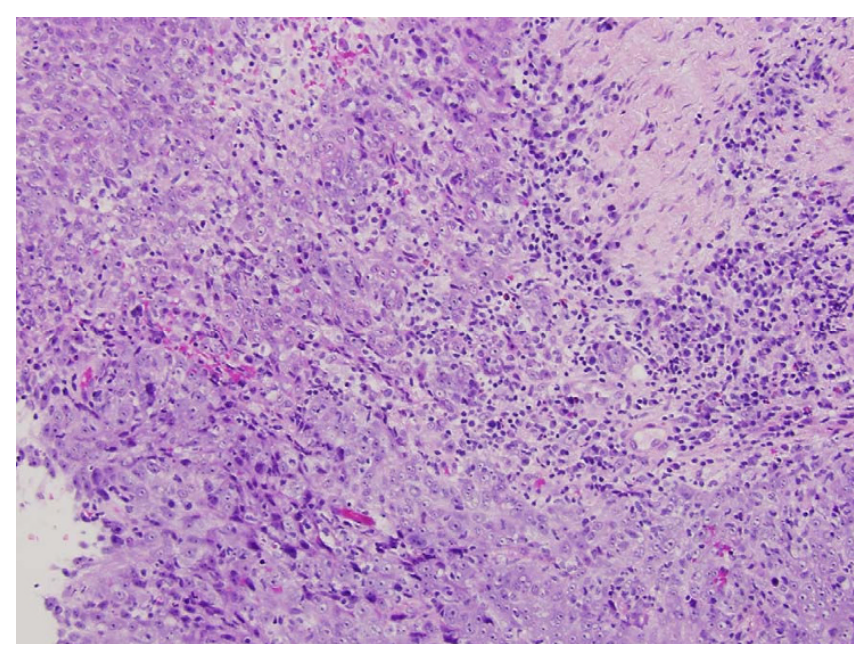

\section{Figure I}

Pathology from original biopsy. Note the characteristic proliferation of cells arranged in a syncytial pattern as well as the vesicular nuclei with prominent nucleoli and areas of keratinization.
1). Stains for the Epstein Barr Virus (EBV) latent membrane protein were negative in the neoplastic cells (Figure 2). This test, however, is not as sensitive or specific as the EBER test which was not available at the time. Neck MRI confirmed a large $4.0 \times 4.7 \times 5.4 \mathrm{~cm}$ mass emanating from the nasopharynx and invading the orifice of the right Eustachian tube. A necrotic cervical lymph node in the right spinal accessory chain was pathologically enlarged at 1.3 $\mathrm{cm}$ and was suspicious for metastatic disease (Figure 3, part A). Chest $\mathrm{x}$-ray and bone scan were negative, and liver function tests were within normal limits. He was staged (AJCC staging 1997) with stage T4N1M0 nasopharyngeal carcinoma.

The patient was referred for chemoradiation treatment, and in $11 / 1997$, he began concurrent cisplatin $(100 \mathrm{mg} /$ $\mathrm{m}^{2}$ ) with concomitant 3D conformal radiation therapy consisting of 66 Gy in 33 fractions of 2.0 Gy. During radiotherapy, he developed severe mucositis, dysphagia and odynophagia requiring temporary PEG tube placement. Post-treatment MRI in 1/1998 showed marked interval decrease in size of the right nasopharyngeal tumor, which now measured approximately $2.2 \times 1.3 \mathrm{~cm}$. Repeat MRI in $2 / 1998$ showed a small quantity of residual fullness in the right nasopharynx (Figure 3, part B). The patient, therefore, subsequently received a stereotactic radiosurgical boost (1200 cGy in one fraction) to the residual abnormality as well as three cycles of adjuvant $75 \mathrm{mg} / \mathrm{m}^{2}$ cisplatin and 5-fluorouracil $1 \mathrm{~g} / \mathrm{m}^{2}(\mathrm{~d} 1-5)$ every 21 days. The patient did not tolerate this regimen well with the development of leukocytopenia and grade IV mucositis, which

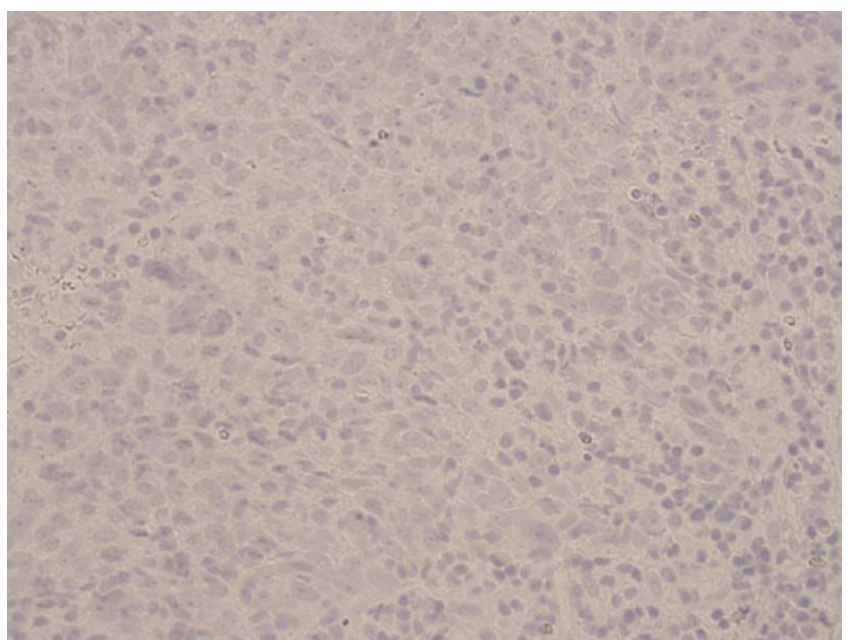

Figure 2

Negative EBV latent membrane staining of biopsy specimen. This test, however, is not as sensitive or specific as the EBER test which became available after this patient was diagnosed. 


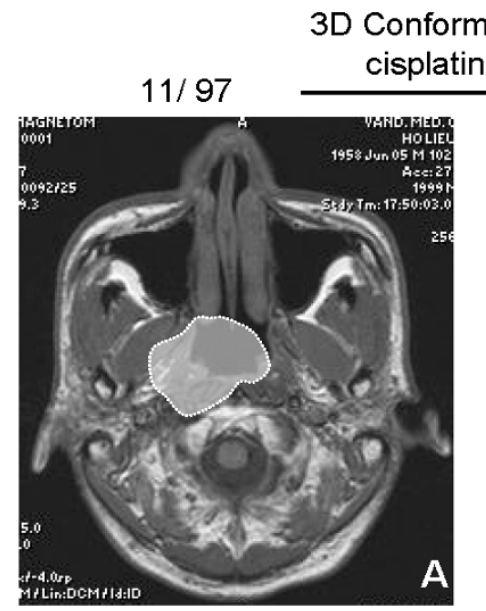

Primary Tumor

A

Tumor Recurrence

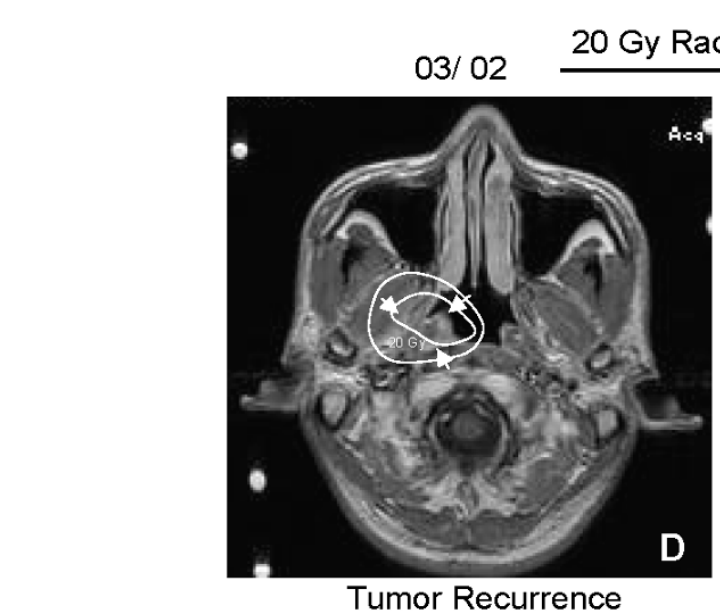

12 Gy Radiosurgery cisplatin/5FU

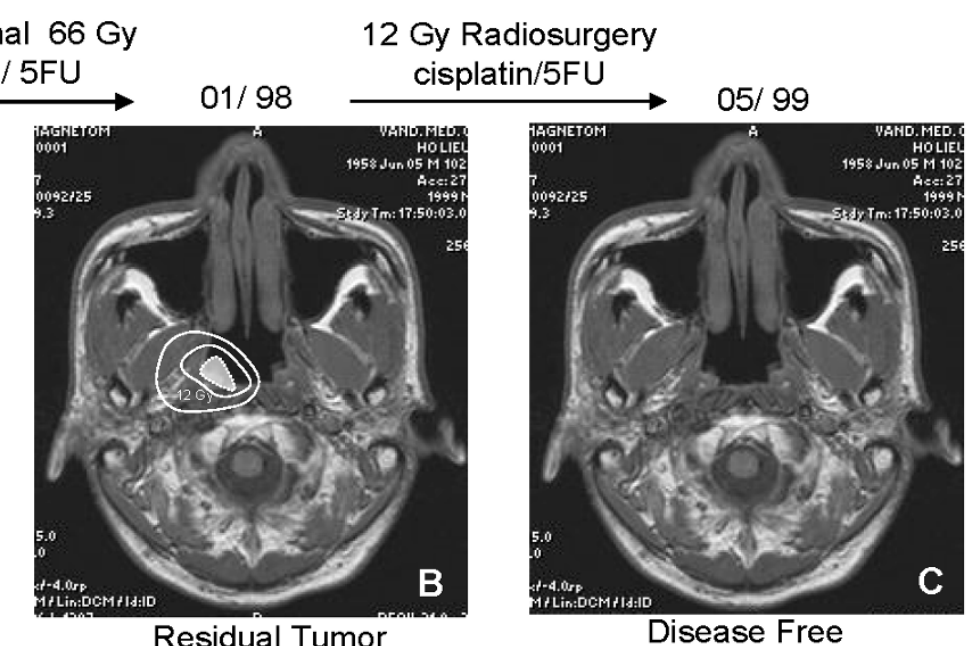

sosurgen

$05 / 02$

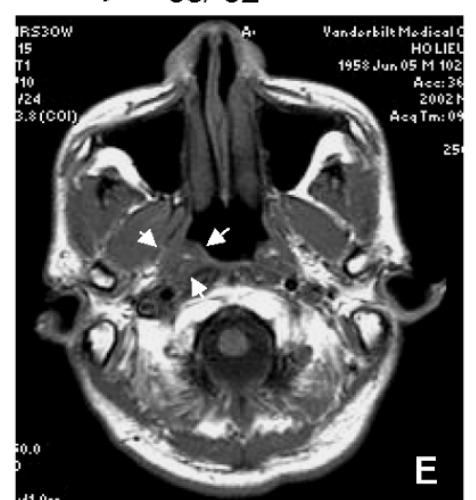

Tumor Shrinkage

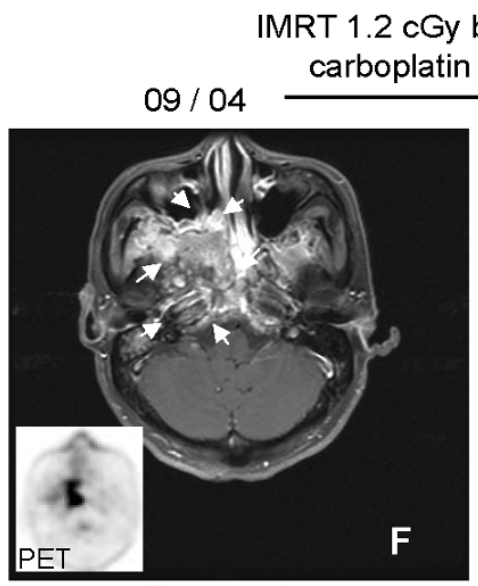

Progression
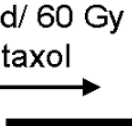

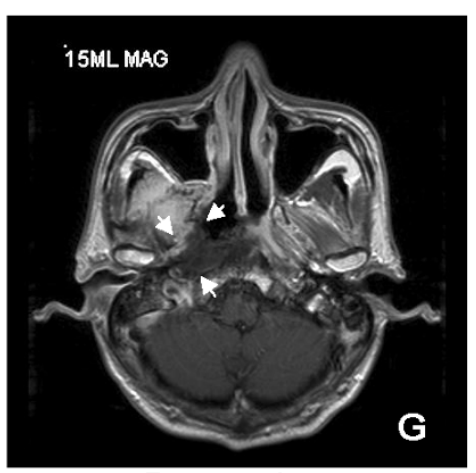

Progression
Cetuximab 
necessitated a $50 \%$ reduction of cisplatin and 5-FU dose on cycles 2 and 3.

By 6/1998, however, the patient had recovered well and showed no evidence of disease on physical and endoscopic examination. MRI 7/1998 showed no obvious disease, only slight soft tissue asymmetry within the nasopharynx. He remained disease-free on frequent follow-up examinations and MRI until 5/1999, when he presented with severe, crippling, lancinating headaches that initiated at the occiput and radiated to his right eye. This was associated with severe fatigue, weakness, and gait instability. An MRI at that time showed no evidence of disease (Figure 3, part $\mathrm{C}$ ). Therefore, the patient was treated conservatively with Gabapentin for presumed neuropathic pain that provided good symptomatic relief. He remained clinically NED for over 2 years.

However, in 11/2001, almost 4 years after the treatment of his initial disease, repeat neck CT showed an interval increase in the asymmetry seen within the soft tissue of his right nasopharynx. Flexible fiberoptic endoscopy revealed a right-sided $1 \mathrm{~cm}$ nasopharyngeal ulcer in the fossa of Rosenmüller. The patient was scheduled for a biopsy of the lesion, but the patient missed the subsequent appointment. In 1/2002, he did return to the clinic but reported symptoms of dizziness, fullness of his ears, fatigue, and occasional headache. He was unable to tolerate solid food. Repeat MRI showed persistent fullness within the right fossa of Rosenmüller. However, the size of the soft tissue abnormality remained unchanged compared with the prior CT. On 1/29/2002, nasal endoscopy with nasopharyngeal biopsy revealed poorly-differentiated nasopharyngeal carcinoma identical to his initial tumor

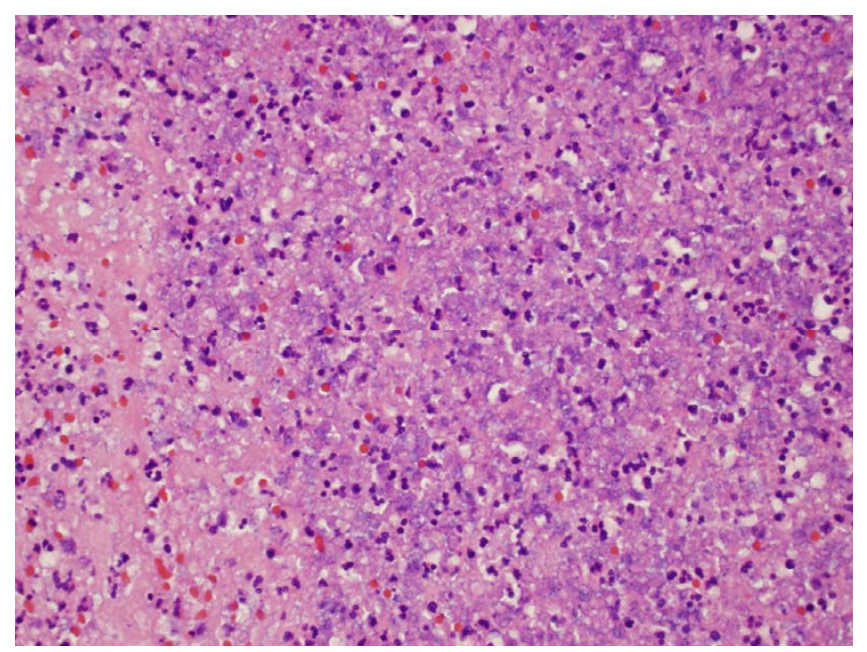

\section{Figure 4}

Pathology from recurrence in $1 / 2002$. Note the increased tumor necrosis compared to 1997. histology (Figure 4). Both MRI and CT in 3/2002 were used to outline the area of recurrence (Figure 3, part D) and he subsequently underwent LINAC-based stereotactic radiosurgery as salvage treatment, delivering $2000 \mathrm{cGy}$ in a single fraction to the periphery of the tumor. The treatment was well tolerated with no major complications.

Repeat MRI in 5/2002 showed a significant decrease in the right-sided nasopharyngeal fullness, but some right parapharyngeal edema remained (Figure 3, part E). The patient noted no significant detriment in his swallowing or speech. Almost one year later, in 4/2003, he reported numbness over the right trigeminal (V1-V3) dermatomes as well as right ear hearing loss and epistaxis. Unfortunately, the patient missed several of his follow-up and MRI appointments.

When he returned to clinic in 9/2004, his MRI showed significant progression of disease. There was a $3 \mathrm{~cm}$ mass that extended through the right skull base and foramen ovale. Additionally, tumor was seen in the right pterygopalatine fossa with destruction of the posterior maxillary sinus extending to the posterior aspect of the right orbit. The tumor also extended laterally to the infratemporal fossa, invading the medial and lateral pterygoid muscles. There was tumor invasion into the longus coli muscle and the perivertebral space with involvement of the jugular tubercle and right jugular foramen. The mass extended inferiorly to the right tonsils, and there were multiple pathologically-enlarged right submandibular and submental lymph nodes (Figure 3, part F).

The patient subsequently received weekly chemotherapy with carboplatin and paclitaxel in 9/2004 for palliation of symptoms. During treatment, patient reported trismus and right ear/jaw pain, and he was started on amoxicillin for a possible infectious process. Repeat MRI of 12/2004 showed slight interval decrease in the size of the skull base component of the nasopharyngeal mass when compared to the 9/2004 study. However, the tumor showed evidence of perineural spread and direct invasion into the skull base and right cavernous sinus as well as into the pterygopalatine fossa and right muscles of mastication.

He continued on weekly carboplatin/paclitaxel. Repeat MRI 2/2005 showed minimal decrease in the size of the nasopharyngeal portion of the mass. Moreover, the patient became leukopenic which prompted cessation of treatment. With limited options by $3 / 2005$, the patient underwent re-irradiation in the form of intensity-modulated radiation therapy (IMRT) given 120 cGy BID for a total of 60 Gy over 5 weeks to gross sites of disease. Treatment significantly overlapped previously irradiated sites from both his initial 3D radiation and radiosurgery treatment. When his white blood count returned to normal on 
3/14/2005, concurrent chemotherapy with carboplatin and paclitaxel was initiated. Concurrent chemoradiation was completed by $4 / 13 / 05$. The patient had developed dysphagia, trismus, persistent xerostomia, grade 3 mucositis, excessive mucus production, and fatigue. Posttreatment MRI 06/05 showed an overall reduction in bulk of the right nasopharyngeal mass and stable appearance of tumor extension into the right cavernous sinus, pteryopalatine fossa, and skull base.

In $08 / 2005$, patient was admitted to inpatient oncology service for 7 days for nausea/emesis along with trismus, decreased oral intake, and resultant dehydration. Extensive scarring of the TMJ from prior tumor and radiation therapy was apparent on exam. To avoid airway compromise and improve nutrition, tracheostomy was performed, and an open gastrostomy tube was placed.

During the hospital admission, MRI showed marked progression of disease. A large necrotic mass centered in the right nasopharyngeal region, extending inferiorly to the level of the right pyriform sinus as well as anteriorly into the infratemporal fossa, was seen. There was again evidence for intracranial extension of disease (Figure 3, part $\mathrm{G})$. Hospice care was recommended to the patient and his family, but the patient declined.

The patient therefore went on to receive cetuximab from $10 / 2005$ to $3 / 2006$, at $400 \mathrm{mg} / \mathrm{m}^{2}$ loading dose and weekly doses of $250 \mathrm{mg} / \mathrm{m}^{2}$. After 3 treatments, he reported a marked decrease in pain and significant improvement in the range of motion in his neck. Repeat MRI 4/2006 revealed no significant disease progression (Figure 3, part H). By this time, the patient had returned to a normal activity level and had pain level ranging $0-2 /$ 10 without medication. Repeat MRI 1/07 remained stable.

Unfortunately, in $2 / 2007$, patient was noted to have a new right-sided facial droop along with a new anaerobic smell and facial pain. He was again reinitiated on weekly cetuximab therapy, at a loading dose of $400 \mathrm{mg} / \mathrm{m}^{2} \mathrm{fol}-$ lowed by weekly maintenance of $250 \mathrm{mg} / \mathrm{m}^{2}$. After his first cycle, he noted improved breathing through his right nostril and decreased odor. By his third cycle, he had developed a grade 2 acneiform rash over his face, scalp, and trunk, which was treated with doxycycline $100 \mathrm{mg}$ BID. He was maintained on cetuximab through $8 / 2007$, when MRI in 8/2007 continued to reveal stable disease. Throughout his 6-month course of cetuximab, he developed significant issues with hypokalemia attributed to cetuximab. This resolved after treatment was discontinued.

The patient remained stable off any systemic therapy until $7 / 2008$. At that time, he developed clinical local progres- sion of disease resulting in epistaxis, increased odor, and breakdown tissue in preauricular region. MRI revealed increasing abnormal enhancement and mass involving the right nasopharyngeal cavity extending into the right cavernous sinus, middle cranial fossa, and dural surface. He was subsequently given $40 \mathrm{mg} / \mathrm{m}^{2}$ methotrexate and clindamycin. There appeared to be an initial clinical response, with decreased erythema in the preauricular region, increased energy, and less odor. However, in 10/ 2008, progression of disease was demonstrated by increased sinus congestion, bleeding, and odor despite aggressive oral hygiene and antibiotic treatment. Additionally, MRI revealed tumor progression into the nasal cavity.

The patient was being considered for a phase I trial, but his tumor was rapidly progressing with worsening of his symptoms. He therefore was placed on weekly $450 \mathrm{mg} / \mathrm{m}^{2}$ 5-fluorouracil (5-FU) and $20 \mathrm{mg} / \mathrm{m}^{2}$ leucovorin in $11 /$ 2008. Surprisingly, his symptoms have improved significantly. During treatment through 1/21/2009, he developed neutropenic fever which required hospitalization and IV antibiotics. Presently, the patient is scheduled to resume his systemic therapy.

A summary of the patient's disease and treatment course can be found in table 1 .

\section{Discussion}

In this case report, we present a patient with locoregionally advanced lympho-epithelial carcinoma of the nasopharynx. Nasopharyngeal carcinoma typically originates in the fossa of Rosenmüller. Since this is a clinically occult site, patients often remain asymptomatic for a relatively prolonged period. Frequently, symptoms of epistaxis, nasal congestion, or otitis media are treated for benign etiologies which defer a definitive diagnosis (mean 7.2 months in one series) [8]. Consequently, more than 90 percent of patients present with locally and/or regionally advanced disease at diagnosis, often with cranial nerve defecits and/or massive cervical adenopathy $[9,10]$. Additionally, a high incidence $(20-40 \%)$ of distant metastases has been reported [11].

Due to anatomical limitation to surgical interventions, radiotherapy with chemotherapy is the preferred choice of treatment. The most pivotal trial investigating the use of chemoradiation in the treatment of nasopharyngeal cancer came from the Intergroup. The chemotherapy regimen consisted of cisplatin during radiation and cisplatin and 5 -FU adjuvant. The 3 year progression free survival was $69 \%$ in the chemoradiation arm versus $24 \%$ with radiation alone. Overall survival at 3 years was $76 \%$ with chemoradiation versus $46 \%$ for radiation alone. Not surprisingly, there was a higher incidence of grade 3-4 
Table I: Summary and outcomes of total radiation and chemotherapy received.

\begin{tabular}{lllll}
\hline Date & Time to progression & Radiation target & Type of radiation therapy & Other therapy \\
\hline II/97-01/98 & N/A & Nasopharynx & $\begin{array}{l}\text { 3D Conformal, 66 Gy/2.0 Gy in 33 } \\
\text { fractions }\end{array}$ & Concurrent Cisplatin + 5 FU \\
\hline $02 / 98$ & 4 years & Nasopharynx & $\begin{array}{l}\text { Stereotactic radiosurgery, I2 Gy in I } \\
\text { fraction }\end{array}$ & Adjuvant Cisplatin + 5 FU \\
\hline $03 / 02$ & 2 years & Nasopharynx & $\begin{array}{l}\text { Stereotactic radiosurgery, 12 Gy in I } \\
\text { fraction }\end{array}$ & None \\
\hline $09 / 04-02 / 05,03 / 05-04 / 05$ & 12 months & Nasopharynx & IMRT, 60 Gy/l.2 Gy in 50 fractions & Concurrent Carboplatin + Taxol \\
\hline $10 / 05-03 / 06,02 / 07-08 / 07$ & 30 months & N/A & N/A & Cetuximab \\
\hline $07 / 08-10 / 08$ & 0 months & N/A & N/A & Methotrexate \\
\hline $11 / 08-$ present & TBD & N/A & N/A & 5 FU + leucovorin
\end{tabular}

Total Radiation Received: 158 Gy to the nasopharynx

leukopenia, nausea, and vomiting with addition of chemotherapy[2]. Multiple subsequent trials have yielded similar results [12-17]. These findings have substantiated chemoradiation for nasopharyngeal cancer. Additionally, the 5 -year overall survival was $37 \%$ for WHO I, 55\% for WHO II, and $60 \%$ for WHO III [18].

However, nasopharyngeal carcinoma still has a recurrence rate of $31 \%$ post-chemoradiation therapy at 3 years [2]. External beam radiation, in the form of intensity-modulated radiation, stereotactic radiosurgery, hyperfractionated radiation, or intracavitary brachytherapy may be options for patients who have a local or regional recurrence. Induction chemotherapy with agents such as cisplatin, taxanes, 5-fluoruracil, or gemcitabine may be considered prior to re-irradiation [19].

Stereotactic radiosurgery (SRS) uses three dimensional planning and techniques to precisely deliver narrowly collimated beams of ionizing radiation in a single high-dose fraction to small $(<4 \mathrm{~cm})$ targets. Administering an SRS boost following external beam RT may improve local control in locally advanced NPC. In one series, all of 23 consecutive patients with stage IV disease receiving an SRS boost following fractionated RT were locally controlled at a mean follow-up of 21 months, although eight subsequently developed regional or distant metastases [20]. Stereotactic techniques and proton beam therapy have also been used to salvage patients with locally recurrent or persistent disease. As an example, in a report of 36 patients with recurrent NPC who were re-irradiated with a radiosurgical boost, the three year locoregional control rate was 56 percent, and a five-year survival of 49 percent $[21,22]$.

Cetuximab, a monoclonal chimeric antibody, inhibits EGFR, which is over-expressed in the vast majority of head and neck cancers [23]. Cetuximab inhibits receptor activity by blocking the ligand binding site. In addition to its potential as a radiation sensitizer $[7,24]$, cetuximab has also been investigated as a single agent, and in combination with cytotoxic agents in patients with advanced head and neck cancer [25-28]. The benefit of cetuximab as a radiation sensitizer was tested in a multinational trial in which 424 patients with locoregionally advanced SCC of the oropharynx, hypopharynx, or larynx were randomly assigned to radiotherapy (once daily, twice daily, or with a concomitant boost, with the specific approach selected by each participating institution) with or without weekly concurrent cetuximab [7]. With a median follow-up of 54 months, the cetuximab-treated group had significantly better median ( 49 versus 29 months) and three-year survival (55 versus 45 percent) compared to those receiving radiation alone. Locoregional control rates were also significantly better ( 50 versus 41 percent), and in a separate report, there was also a suggestion of a higher laryngeal preservation rate in the cetuximab group ( 88 versus 80 percent at three years, respectively) [24]. The cumulative rate of distant metastases at two years was similar (16 versus 17 percent, respectively) [7].

Cetuximab has also been shown to increase locoregional disease control as well as stabilizing distant metastasis when given alone [4]. In the case of our patient, after 
receiving 158 Gy to the nasopharynx, additional radiotherapy was no longer deemed a viable option. Since the patient had failed multiple chemotherapy regimens including cisplatin, 5-FU, carboplatin, and paclitaxel, cetuximab was considered a reasonable choice in this patient. Anecdotally, it provided over 30 months of progression-free tumor control. Toxicities from this therapy included acneiform rash and hypokalemia.

In summary, lympho-epithelial carcinoma of the nasopharynx often exhibits a protracted course and responds to multiple treatment modalities. Up-front standard of care therapy includes concurrent cisplatin and radiation followed by adjuvant cisplatin and 5-FU. More commonly, induction chemotherapy is used for better tolerance. Despite excellent 5 year survival data with this treatment approach, a substantial proportion of patients recur, as illustrated by our patient. After exhausting multiple therapeutic strategies, EGFR inhibition afforded him over 30 months of progression-free tumor control and significant palliation.

\section{Consent}

Verbal informed consent was obtained from the patient for publication of the case report and accompanying images.

\section{Competing interests}

The authors declare that they have no competing interests.

\section{Authors' contributions}

FW conceived of the study, participated in its design and coordination, and the writing of the manuscript. EY participated in the study design and coordination and writing of the manuscript. CW participated in the study design and coordination. KE participated in study design and coordination. CG participated in study design and coordination. AC participated in the study design, coordination, and writing of the manuscript. All authors read and approved the final manuscript.

\section{References}

I. Ho JH: An epidemiologic and clinical study of nasopharyngeal carcinoma. Int J Radiat Oncol Biol Phys 1978, 4:182-198.

2. Al-Sarraf M, LeBlanc M, Giri PG, Fu KK, Cooper J, Vuong T, Forastiere AA, Adams G, Sakr WA, Schuller DE, Ensley JF: Chemoradiotherapyversus radiotherapy in patients with advanced nasopharyngeal cancer: Phase iii randomized intergroup study 0099. I Clin Oncol 1998, 16:1310-1317.

3. Fu KK, Pajak TF, Trotti A, Jones CU, Spencer SA, Phillips TL, Garden AS, Ridge JA, Cooper JS, Ang KK: A radiation therapy oncology group (rtog) phase iii randomized study to compare hyperfractionation and two variants of accelerated fractionation to standard fractionation radiotherapy for head and neck squamous cell carcinomas: First report of rtog 9003 . Int J Radiat Oncol Biol Phys 2000, 48:7-16.

4. Marshall J: Clinical implications of the mechanism of epidermal growth factor receptor inhibitors. Cancer 2006, 107:1207-1218.
5. Vermorken JB, Herbst RS, Leon X, Amellal N, Baselga J: Overview of the efficacy of cetuximab in recurrent and/or metastatic squamous cell carcinoma of the head and neck in patients who previously failed platinum-based therapies. Cancer 2008, I I 2:27|0-27| 9 .

6. Vermorken JB, Trigo J, Hitt R, Koralewski P, Diaz-Rubio E, Rolland F, Knecht R, Amellal N, Schueler A, Baselga J: Open-label, uncontrolled, multicenter phase ii study to evaluate the efficacy and toxicity of cetuximab as a single agent in patients with recurrent and/or metastatic squamous cell carcinoma of the head and neck who failed to respond to platinum-based therapy. I Clin Oncol 2007, 25:217I-2I 77.

7. Bonner JA, Harari PM, Giralt J, Azarnia N, Shin DM, Cohen RB, Jones CU, Sur R, Raben D, Jassem J, Ove R, Kies MS, Baselga J, Youssoufian $\mathrm{H}$, Amellal N, Rowinsky EK, Ang KK: Radiotherapy plus cetuximab for squamous-cell carcinoma of the head and neck. $N$ Engl J Med 2006, 354:567-578.

8. Leong JL, Fong KW, Low WK: Factors contributing to delayed diagnosis in nasopharyngeal carcinoma. J Laryngol Otol 1999, I 1 3:633-636.

9. Fandi A, Altun M, Azli N, Armand JP, Cvitkovic E: Nasopharyngeal cancer: Epidemiology, staging, and treatment. Semin Oncol 1994, 2 1:382-397.

10. Hsu MM, Tu SM: Nasopharyngeal carcinoma in taiwan. Clinical manifestations and results of therapy. Cancer 1983, 52:362-368.

II. Ahmad A, Stefani S: Distant metastases of nasopharyngeal carcinoma: A study of $\mathbf{2 5 6}$ male patients. J Surg Oncol 1986, 33:194-197.

12. Ma J, Mai HQ, Hong MH, Min HQ, Mao ZD, Cui NJ, Lu TX, Mo HY: Results of a prospective randomized trial comparing neoadjuvant chemotherapy plus radiotherapy with radiotherapy alone in patients with locoregionally advanced nasopharyngeal carcinoma. J Clin Oncol 200I, 19:1350-1357.

13. Chan AT, Teo PM, Ngan RK, Leung TW, Lau WH, Zee B, Leung SF, Cheung FY, Yeo W, Yiu HH, Yu KH, Chiu KW, Chan DT, Mok T, Yuen KT, Mo F, Lai M, Kwan WH, Choi P, Johnson PJ: Concurrent chemotherapy-radiotherapy compared with radiotherapy alone in locoregionally advanced nasopharyngeal carcinoma: Progression-free survival analysis of a phase iii randomized trial. J Clin Oncol 2002, 20:2038-2044.

14. Chi KH, Chang YC, Guo WY, Leung MJ, Shiau CY, Chen SY, Wang LW, Lai YL, Hsu MM, Lian SL, Chang CH, Liu TW, Chin YH, Yen SH, Perng $\mathrm{CH}$, Chen KY: A phase iii study of adjuvant chemotherapy in advanced nasopharyngeal carcinoma patients. Int J Radiat Oncol Biol Phys 2002, 52:1238-1244.

15. Lin JC, Jan JS, Hsu CY, Liang WM, Jiang RS, Wang WY: Phase iii study of concurrent chemoradiotherapy versus radiotherapy alone for advanced nasopharyngeal carcinoma: Positive effect on overall and progression-free survival. J Clin Oncol 2003, $21: 63$ I-637.

16. Zhang L, Zhao C, Peng PJ, Lu LX, Huang PY, Han F, Wu SX: Phase iii study comparing standard radiotherapy with or without weekly oxaliplatin in treatment of locoregionally advanced nasopharyngeal carcinoma: Preliminary results. J Clin Oncol 2005, 23:846 I-8468.

17. Lee AW, Lau WH, Tung SY, Chua DT, Chappell R, Xu L, Siu L, Sze WM, Leung TW, Sham JS, Ngan RK, Law SC, Yau TK, Au JS, O'Sullivan B, Pang ES, O SK, Au GK, Lau JT: Preliminary results of a randomized study on therapeutic gain by concurrent chemotherapy for regionally-advanced nasopharyngeal carcinoma: Npc-990I trial by the hong kong nasopharyngeal cancer study group. I Clin Oncol 2005, 23:6966-6975.

18. Al-Sarraf Muhyi, LeBlanc Michael, Giri PGS, Fu Karen, Cooper Jay, Vuong T, Forastiere Arlene, Adams George, Sakr Wael, Schuller David, Ensley J: Superiority of five year survival with chemoradiotherapy (ct-rt) vs radiotherapy in patients (pts) with locally advanced nasopharyngeal cancer (npc). Intergroup (0099) (swog 8892, rtog 8817, ecog 2388) phase iii study: Final report. Proc Am Soc Clin Oncol 200I, 20:227a.

19. Chua DT, Sham JS, Au GK: Induction chemotherapy with cisplatin and gemcitabine followed by reirradiation for locally recurrent nasopharyngeal carcinoma. Am J Clin Oncol 2005, 28:464-47I.

20. Tate DJ, Adler JR Jr, Chang SD, Marquez S, Eulau SM, Fee WE, Pinto $H$, Goffinet DR: Stereotactic radiosurgical boost following 
radiotherapy in primary nasopharyngeal carcinoma: Impact on local control. Int J Radiat Oncol Biol Phys 1999, 45:915-92I.

21. Pai PC, Chuang CC, Wei KC, Tsang NM, Tseng CK, Chang CN: Stereotactic radiosurgery for locally recurrent nasopharyngeal carcinoma. Head Neck 2002, 24:748-753.

22. Law SC, Lam WK, Ng MF, Au SK, Mak WT, Lau WH: Reirradiation of nasopharyngeal carcinoma with intracavitary mold brachytherapy: An effective means of local salvage. Int J Radiat Oncol Biol Phys 2002, 54:1095-III3.

23. Chung CH, Ely K, McGavran L, Varella-Garcia M, Parker J, Parker N, Jarrett C, Carter J, Murphy BA, Netterville J, Burkey BB, Sinard R, Cmelak A, Levy S, Yarbrough WG, Slebos RJ, Hirsch FR: Increased epidermal growth factor receptor gene copy number is associated with poor prognosis in head and neck squamous cell carcinomas. J Clin Oncol 2006, 24:4170-4I76.

24. Robert F, Ezekiel MP, Spencer SA, Meredith RF, Bonner JA, Khazaeli MB, Saleh MN, Carey D, LoBuglio AF, Wheeler RH, Cooper MR, Waksal HW: Phase i study of anti - epidermal growth factor receptor antibody cetuximab in combination with radiation therapy in patients with advanced head and neck cancer. I Clin Oncol 200I, 19:3234-3243.

25. Kies MS, Garden AS, Holsinger C, Papadimitrakopoulou V, El-Naggar AK, Gillaspy K, Lewin J, Lu C, Villalobos S, Glisson BS: Induction chemotherapy (ct) with weekly paclitaxel, carboplatin, and cetuximab for squamous cell carcinoma of the head and neck (hn). J Clin Oncol (Meeting Abstracts) 2006, 24:5520.

26. Burtness B, Goldwasser MA, Flood W, Mattar B, Forastiere AA: Phase iii randomized trial of cisplatin plus placebo compared with cisplatin plus cetuximab in metastatic/recurrent head and neck cancer: An eastern cooperative oncology group study. J Clin Oncol 2005, 23:8646-8654.

27. Pfister DG, Su YB, Kraus DH, Wolden SL, Lis E, Aliff TB, Zahalsky AJ, Lake S, Needle MN, Shaha AR, Shah JP, Zelefsky MJ: Concurrent cetuximab, cisplatin, and concomitant boost radiotherapy for locoregionally advanced, squamous cell head and neck cancer: A pilot phase ii study of a new combined-modality paradigm. J Clin Oncol 2006, 24:1072-1078.

28. Vermorken J, Mesia R, Vega V, Remenar E, Hitt R, Kawecki A, Rottey $S$, Amellal N, Cupissol D, Licitra L: Cetuximab extends survival of patients with recurrent or metastatic scchn when added to first line platinum based therapy - results of a randomized phase iii (extreme) study. J Clin Oncol (Meeting Abstracts) 2007, 25:.

\section{Publish with Bio Med Central and every scientist can read your work free of charge}

"BioMed Central will be the most significant development for disseminating the results of biomedical research in our lifetime. "

Sir Paul Nurse, Cancer Research UK

Your research papers will be:

- available free of charge to the entire biomedical community

- peer reviewed and published immediately upon acceptance

- cited in PubMed and archived on PubMed Central

- yours - you keep the copyright

Submit your manuscript here:

http://www.biomedcentral.com/info/publishing_adv.asp
BioMedcentral 